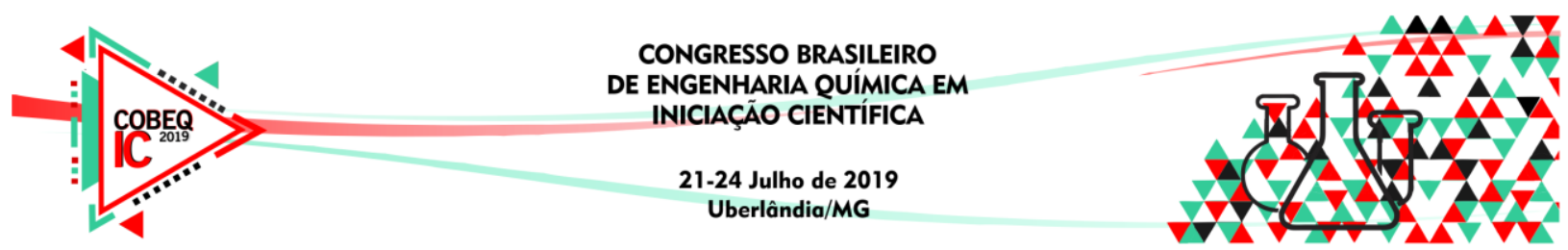

\title{
ESTUDO DA SEDIMENTAÇÃO DE MICROESFERAS DE VIDRO EM MEIO NÃO NEWTONIANO UTILIZANDO A TÉCNICA DE ATENUAÇÃO DE RAIOS GAMA
}

\section{H. ARROYO, F. M. FAGUNDES, N. B. C. SANTOS, F. O. AROUCA e J. J. R. DAMASCENO}

\author{
Universidade Federal de Uberlândia, Faculdade de Engenharia Química \\ E-mail para contato: vichebling2810@gmail.com
}

RESUMO - A sedimentação em fluidos não newtonianos tem sido alvo de estudo em processos de exploração de petróleo, visto que, quando os poços não estão em operação, ocorre a separação gravitacional sólido-líquido que pode aumentar a probabilidade dos desgastes de equipamentos bem como a fratura das formações devido às altas pressões de bombeio e hidrostática. Neste contexto, este projeto tem como objetivo avaliar a sedimentação gravitacional e em batelada de partículas em meio aquoso polimérico não newtoniano utilizando a Técnica de Atenuação de Raios Gama (TARG). Esta técnica permite o monitoramento da concentração volumétrica das partículas sem interferir na estabilidade e configuração do sistema estudado. A partir dos resultados experimentais, observou-se o comportamento da concentração de sólidos na sedimentação bem como a acomodação do sedimento.

\section{INTRODUÇÃO}

Conforme Martins et al. (2015) uma das principais fontes de energia não renováveis no mundo é proveniente do petróleo. Desta forma, diversos investimentos e pesquisas têm sido realizados a fim de trazerem melhorias aos processos envolvidos. Uma dessas etapas em desenvolvimento é a perfuração dos poços, sendo assim, torna-se de suma importância o estudo dos fluidos de perfuração.

Segundo Guimarães e Rossi (2007) os fluidos de perfuração devem apresentar como funções o resfriamento da broca, a retirada dos cascalhos gerados na perfuração, bem como a manutenção da estabilidade do poço. Além disso, de acordo com Santos (2007), são fluidos cuja viscosidade diminui quando submetidos a uma elevada taxa de cisalhamento, favorecendo a sedimentação.

O trabalho de Kynch (1952) destaca-se por ser a primeira teoria de sedimentação sólido-líquido. Nele, o autor descreveu a sedimentação como sendo uma operação unitária em que a concentração de sólidos foi obtida de forma unidirecional e com o tempo. Além disso, verificou a existência de quatro regiões na sedimentação em batelada: (i) líquido clarificado, nesta região a concentração de sólidos é nula, (ii) sedimentação livre, a concentração de sólidos é igual a inicial e a velocidade de sedimentação é constante, (iii) intermediária, apresenta velocidade de sedimentação decrescente e a concentração entre a inicial da suspensão e a final do sedimento e (iv) de sedimento, nesta região a velocidade de sedimentação é nula e a concentração de sólidos é máxima.

A técnica de atenuação de raios gama (TARG) é um método que permite a determinação da concentração volumétrica de sólidos em meios concentrados e também não interfere na estabilidade e configuração das suspensões em análise. 


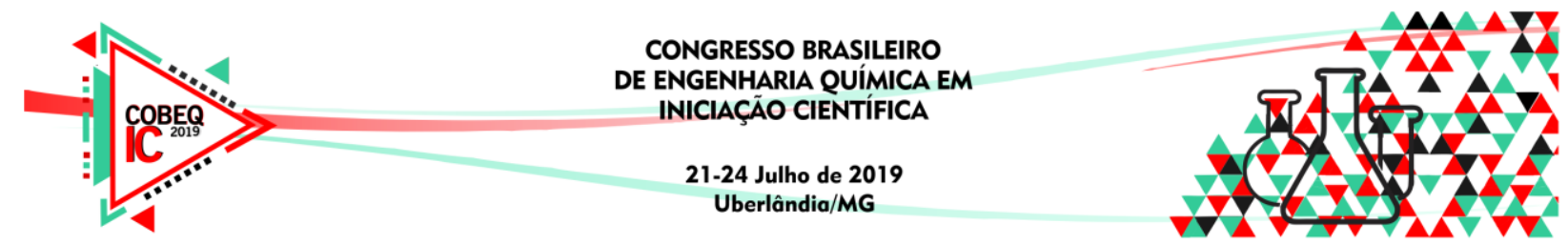

Diante deste cenário, este trabalho objetivou avaliar a sedimentação de partículas de microesferas de vidro coloridas na sedimentação gravitacional e em batelada em fluido pseudoplástico. A presença da cor nas partículas permitiu verificar a formação de canais preferenciais de sedimentação e a acomodação das partículas no sedimento.

\section{METODOLOGIA}

Com a finalidade de realizar os testes de sedimentação foram feitas suspensões pseudoplásticas de carboximetil celulose (CMC), visto que, de acordo com Nóbrega e Amorin (2015), este polímero pode ser utilizado como agente viscosificante. Sendo assim, foram preparadas soluções de CMC $0,6 \%$ em massa com os componentes e quantidades apresentados na Tabela 1.

Tabela 1- Solução aquosa polimérica.

\begin{tabular}{|c|c|}
\hline Componente & Quantidade \\
\hline Água & $497 \mathrm{~mL}$ \\
\hline Formaldeído & $3 \mathrm{~mL}$ \\
\hline CMC & $3 \mathrm{~g}$ \\
\hline
\end{tabular}

A utilização do formaldeído foi dada de acordo às indicações encontradas em Moreira (2014). Este bactericida foi utilizado para impedir a proliferação de microrganismos que podem degradar o CMC.

A analise reológica foi realizada em triplicata no viscosímetro Brookfield DV2T com spindle SC4-34, cuja geométrica é cone-placa e o controle de temperatura foi realizado em banho ultra termostático da Quimis, modelo Q214M2. Para a aquisição de dados foi utilizado o software Rheocalc T.

O procedimento experimental para a obtenção do comportamento reológico iniciou-se com pré-cisalhamento na maior taxa possível do spindle utilizado $\left(56 \mathrm{~s}^{-1}\right)$ durante 1 minuto, em seguida, foi aplicada uma taxa constante de deformação. Este procedimento foi realizado repetidamente para as taxas de 5 até $50 \mathrm{~s}^{-1}$, em intervalos de $5 \mathrm{~s}^{-1}$. Os resultados encontrados foram ajustados ao modelo reológico de Power Law (Equação 1).

$$
\tau=m \gamma^{n}
$$

sendo $m$ e $n$ os índices de consistência e de comportamento, respectivamente, $\tau$ a tensão cisalhante, $\gamma$ taxa de deformação.

Com o objetivo de analisar a sedimentação de partículas, utilizou-se a solução apresentada na Tabela 1 misturada com microesferas de vidro cujo mesh estava na faixa de 212 a $108 \mu \mathrm{m}$ e com esfericidade de $80 \%$, sendo estas pintadas com tinta spray azul a fim de facilitar a visualização dos canais de sedimentação. 


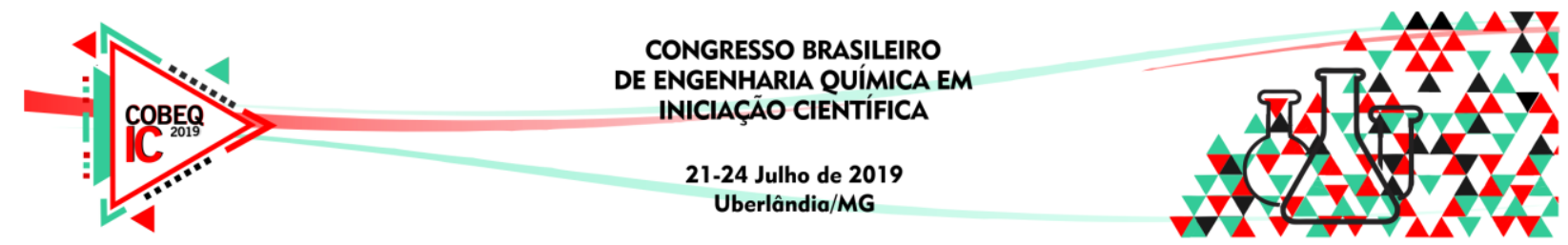

A quantidade de microesferas de vidro utilizada foi determinada a partir da equação de concentração volumétrica de sólidos representada pela Equação 2

$$
\varepsilon_{s}=\frac{\frac{m_{s}}{\rho_{s}}}{\frac{m_{s}}{\rho_{s}}+V_{f}}
$$

em que $V_{f}$ é o volume do fluido e $\rho_{s}, m_{s}, \varepsilon_{s}$ são a massa específica, a massa e a concentração volumétrica de sólidos, respectivamente.

Desta forma, com a utilização da massa específica das microesferas $\left(2,5 \mathrm{~g} / \mathrm{cm}^{3}\right)$, encontrou-se a massa de sólidos a ser colocada na solução para obter uma suspensão de concentração volumétrica de $4 \%$. O fluido preparado e homogeneizado foi vertido em um tubo de vidro cujo fundo era fechado e este acoplado ao sistema de direcionamento/detecção de radiação como mostra a Figura 1.

Figura 1 - Sistema de direcionamento/detecção de radiação.

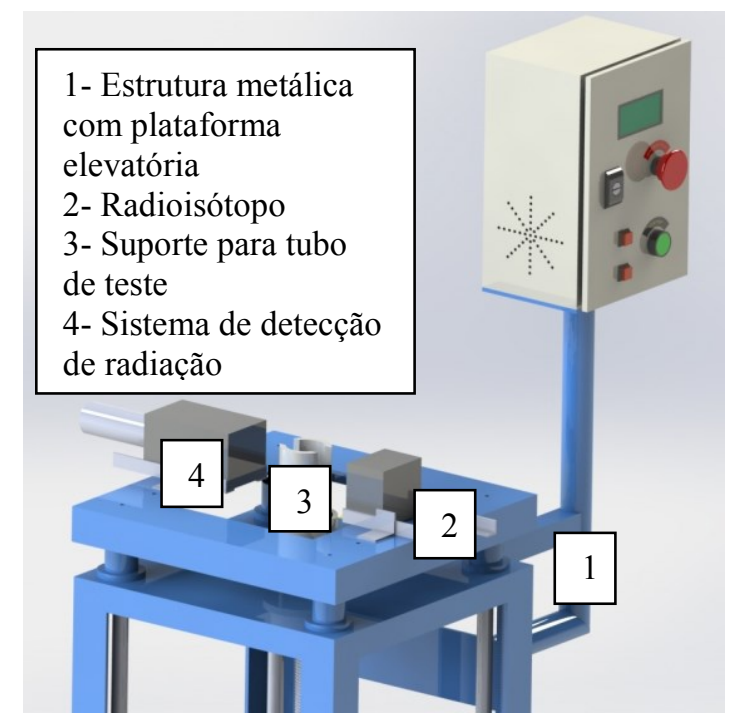

\subsection{Monitoramento da concentração volumétrica de sólidos}

Com o objetivo de monitorar a concentração volumétrica de sólidos para diferentes posições e tempos, empregou-se a Técnica de Atenuação de Raios Gama. Para tanto, utilizouse a equação de Lambert (GARDNEY e ELY-JR, 1967) representada na Equação 3:

$$
\ln \left(\frac{R_{0}}{R}\right)=\beta \varepsilon_{s}
$$

sendo $\beta$ uma constante de calibração, $R_{0}$ e $R$ a intensidade de radiação corrigida pelo tempo de resolução do sistema $(t=0,000169 \mathrm{~s})$ antes e após a passagem pelo meio atenuante. 


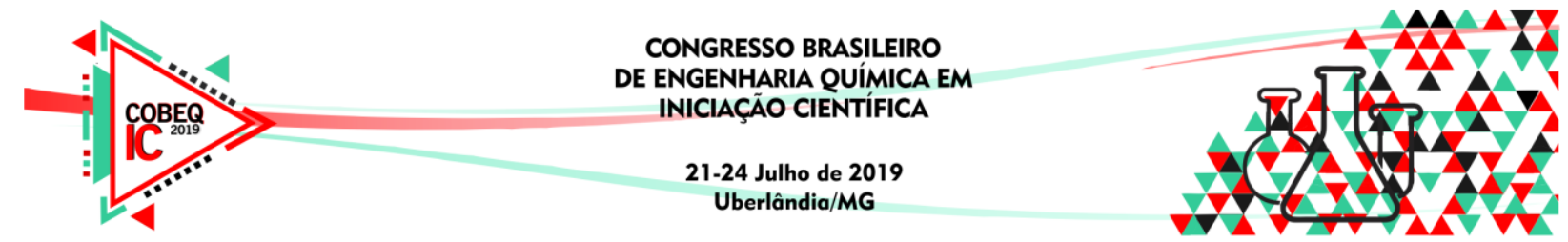

\section{RESULTADOS E DISCUSSÕES}

O comportamento reológico da solução aquosa polimérica foi atestado pela avaliação dos índices de comportamento e de consistência do modelo de Power-Law, obtendo-se para uma solução de CMC 0,6\% um índice de consistência de 0,70266 $\mathrm{Pa}^{n}$, índice de comportamento 0,6853 e $r^{2}$ de 0,9992 , comprovando o caráter pseudoplástico.

A análise da sedimentação foi realizada nas posições $z=0,5,10$ e $20 \mathrm{~cm}$ acima da base, conforme apresentado na Figura 2.

Figura 2 - Perfis de sedimentação de microesferas de vidro em meio não newtoniano nas posições: (a) $0,5 \mathrm{~cm}, 10 \mathrm{~cm}$ e $20 \mathrm{~cm}$, (b) $0,5 \mathrm{~cm}$, (c) $10 \mathrm{~cm}$ e (d) $20 \mathrm{~cm}$.
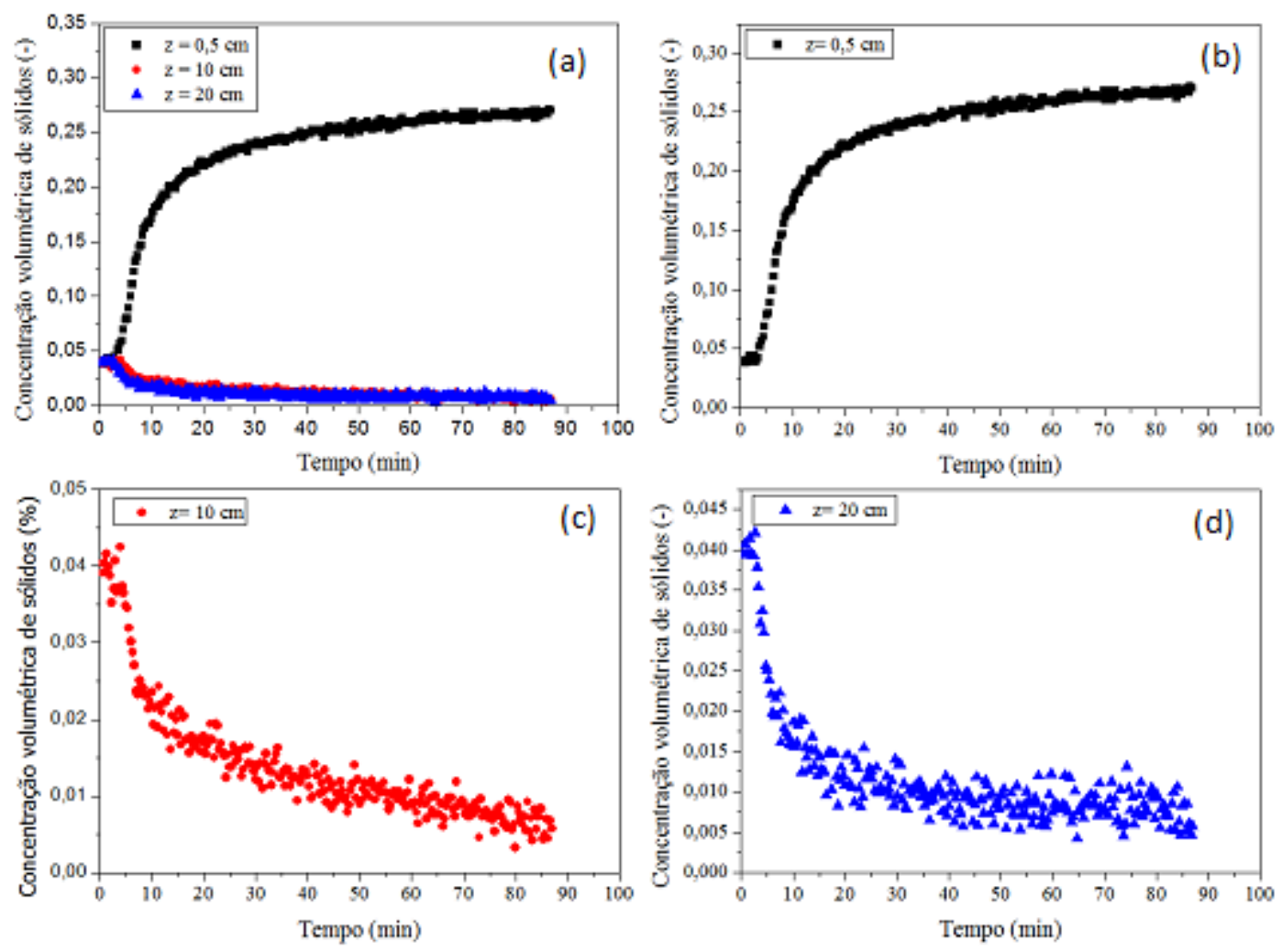

De acordo com a Figura 2, foi possível observar que na altura $\mathrm{z}=0,5 \mathrm{~cm}$ acima da base ocorreu o aumento da concentração volumétrica de sólidos, indicando a formação do sedimento. Enquanto que nas posições $\mathrm{z}=10 \mathrm{e} 20 \mathrm{~cm}$ observou-se o decréscimo da concentração volumétrica de sólidos, indicando a formação da região de líquido clarificado.

O processo de separação no fluido em estudo aconteceu de forma acentuada nos primeiros 20 minutos do experimento. Este comportamento foi observado em estudos de sedimentação com aglomeração de partículas, como apresentado em Daugan et al. (2004) em que partículas deformaram o fluido pseudoplástico, criando um canal de menor viscosidade acima delas e, portanto, favorecendo a sedimentação das partículas.

Além disso, observou-se na Figura 2 que a curva de aumento de concentração de sólidos teve comportamento logarítmico e a curva de decaimento de sólidos foi exponencial. 


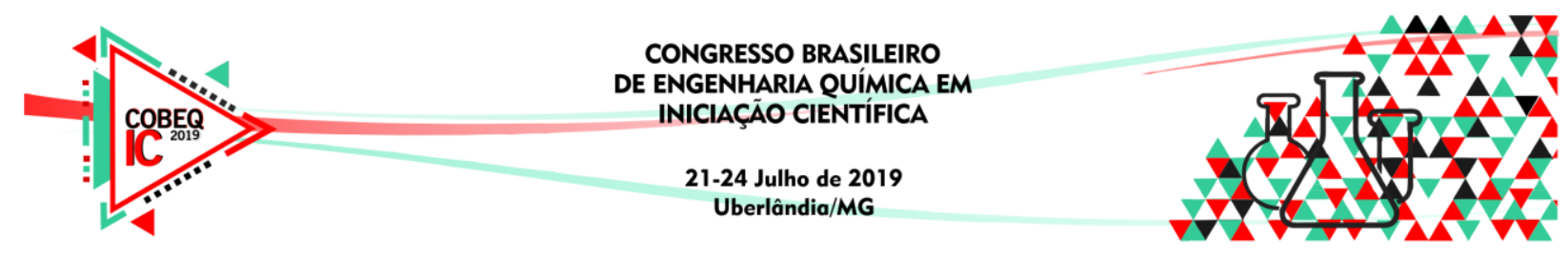

Na Figura 3 estão apresentadas fotografias da vidraria de teste com o sedimento formado após 1 h30 de experimento.

Figura 3- Fotografia (a) da sedimentação de microesferas de vidro durante o experimento e (b) do sedimento .
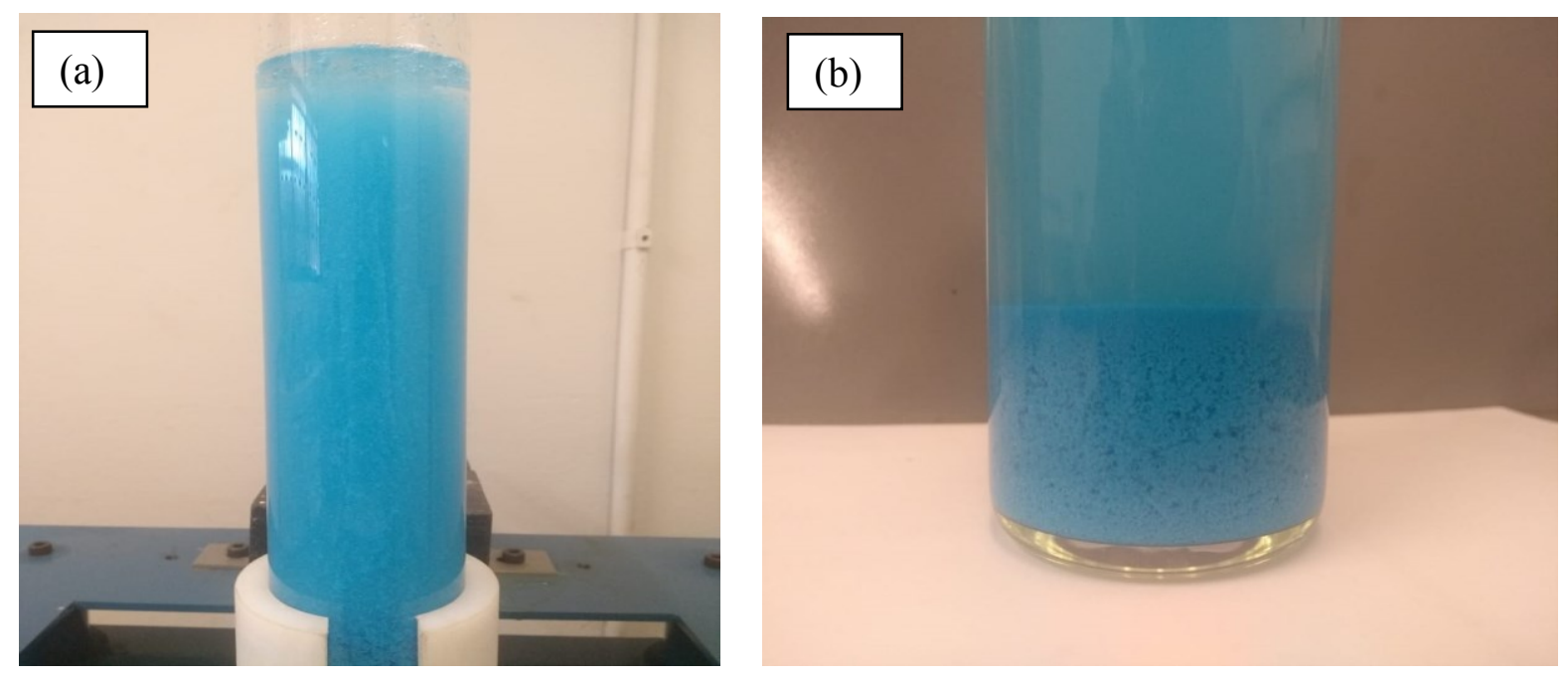

Devido à coloração azul das partículas, foi possível observar a sedimentação de aglomerados e a resuspensão de partículas (Figura 3.a). Já na Figura 3.b notou-se que a acomodação dos sólidos no sedimento não foi perfeita, uma vez que no sedimento havia espaços sem sólidos. Estes espaços observados foram formados também em razão nos aglomerados.

\section{CONCLUSÃO}

O monitoramento da concentração volumétrica de sólidos permitiu verificar a formação das regiões de líquido clarificado, intermediária e de sedimento. As curvas referentes ao aumento da concentração apresentaram comportamento logarítmico e as curvas que representam a diminuição da concentração local de sólidos mostraram comportamento exponencial. Além disso, pôde-se concluir que o processo de sedimentação das microesferas de vidro no fluido em estudo foi rápido, não apresentando grandes variações de concentração volumétrica de sólidos após 20 minutos do início da separação. Por fim, a coloração das microesferas de vidro permitiu verificar a aglomeração e a resuspensão das partículas, além da presença de espaços no sedimento.

\section{NOMENCLATURA}

$\tau$ - Tensão cisalhante $\left[\mathrm{ML}^{-1} \mathrm{~T}^{-2}\right]$

$\gamma$ - Taxa de deformação $\left[\mathrm{T}^{-1}\right]$

$m$ - Índice de consistência [MLT $\left.{ }^{-2+n}\right]$

$n$ - Índice de comportamento [-]

$R$ - Contagem corrigida de radiação que atravessam o meio físico $\left[\mathrm{T}^{-1}\right]$ 


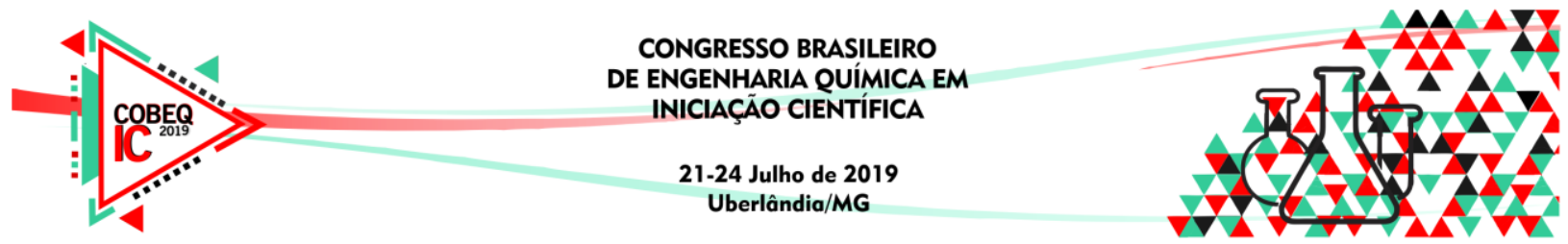

$R_{0}$ - Contagem corrigida de radiação antes da passagem pelo meio atenuador $\left[\mathrm{T}^{-1}\right]$

$\varepsilon_{s}$ - Concentração volumétrica de sólidos [-]

$\beta$ - Constante de calibração [-]

$t$ - Tempo de resolução do sistema $\left[\mathrm{T}^{-1}\right]$

\section{AGRADECIMENTOS}

Os autores agradecem à CAPES, ao CNPQ, à FAPEMIG, à PETROBRAS e à Faculdade de Engenharia Química da Universidade Federal de Uberlândia pelo auxílio financeiro que tornou possível a realização deste trabalho.

\section{REFERENCIAS}

AROUCA, F. O. Uma Contribuição ao Estudo da Sedimentação Gravitacional em Batelada. Tese (Doutorado), Uberlândia, UFU, 2007.

DAMASCENO, J. J. R. Uma Contribuição ao Estudo do Espessamento Contínuo. Tese (Doutorado), Rio de Janeiro, UFRJ, 1992.

DAUGAN, S.; TALINI, L.; HERZHAFT, B.; ALLAIN, C. Aggregation of particles settling in shear thinning fluids. Part 2. Three particle aggregation. The European Physical Journal E, vol. 9, p. 55-62, 2002

FAGUNDES, F. M. Estudo da estabilidade da suspensão constituinte do fluido $\mathrm{Br}$ Mul/Petrobrás. Dissertação (Mestrado), Uberlândia, UFU, 2015.

GARDNER, R. P.; ELY- JR, R.L. Radioisotope Measurement Applications in Engineering, Reinhold, New York, 1967.

GUIMARÃES, I. B; ROSSI, L. F. S. Estudo dos constituintes dos fluidos de perfuração: Proposta de uma formulação otimizada e ambientalmente correta. $4^{\circ}$ Congresso Brasileiro de Petróleo e Gás - PDPETRO, Campinas, São Paulo. 2017.

KYNCH, G. J. A theory of sedimentation. Trans. Amer. Soc., p. 166- 176, 1952.

MARTINS, S. S. S.; SILVA, M. P.; AZEVEDO, M. O.; SILVA, V. P. Produção de petróleo e impactos ambientais: algumas considerações, Rio Grande do Norte, p. 55, nov. 2015. HOLOS, Ano 31, vol. 6.

MOREIRA, B. A. Estudo da sedimentação em suspensões de fluido com características reológicas pseudoplásticas. Tese (Doutorado), Uberlândia, UFU, 2014.

NÓBREGA, K. C.; AMORIM, L. V. Influência da massa molar de CMC no comportamento reológico e de filtração de suspensões argilosas. Cerâmica, v. 61, p. 399-408, 2015.

SANTOS, M. B. Perfuração de poços de petróleo: fluidos de perfuração. Revista de divulgação do Projeto Universidade Petrobras e IF Fluminense v. 2, n. 1, p. 121-127, 2012 